Revista Iberoamericana, Vol. LXIX, Núm. 205, Octubre-Diciembre 2003, 797-817

\title{
CONFIGURACIONES POLÍTICO-ERÓTICAS DEL BOLERO EN LA NARRATIVA CARIBEÑA
}

\author{
POR \\ JoRge ROSARIO VÉLEZ \\ Long Island University
}

\begin{abstract}
Tristezas me dan tus quejas mujer profundo dolor que dudes de mí no hay pena de amor que deje entrever cuánto sufro y padezco por ti... José “Pepe” Sánchez
\end{abstract}

Proteica, sí... la transfiguración de “Tristezas” después de que el sastre José "Pepe” Sánchez propagara la sencilla melodía en Santiago de Cuba desde 1885. Tan proteica que el género musical ya existía sin nominalización alguna. Un siglo después, el bolero aún difunde sus tristezas y ensoñaciones amorosas con identidad y pluralidad propia desde diversas plataformas. ${ }^{1}$ Sánchez, tan desconocedor como Colón o Cervantes, murió ignorando los alcances de su fundación. Pero, ¿̇lo supieron acaso los trovadores santiagueros que emigraban a La Habana y deleitaban a la concurrencia en los puertos? No. Tampoco lo supo el bolerista Lucho Gatica a quien Vargas Llosa homenajea en La tía Julia y el escribidor. Ni Los Panchos, ni Bola de Nieve, ni La Lupe conocieron su difusión y no pudieron escucharse como fondo intertextual en las películas de Pedro Almodóvar. Mucho menos Agustín Lara cuyos boleros "Señora tentación” y "Arráncame la vida" titulan una telenovela latinoamericana y el texto que saca del anonimato a Ángeles Mastretta. ¡Vaya trascendencia desconocida! ¡Vaya calidad proteica! Bolero, la efervescencia de una expresión popular en voz del trovador funda su perennidad: texto oral en los espacios públicos, texto difundido desde la radio, la vellonera, el cine, la telenovela, el disco compacto ... y texto apropiado por la literatura. ¿Es este el desenlace de la historia de un amor iniciada en Santiago de Cuba por José "Pepe" Sánchez? No.

Muchas noches de rondas aguardan gracias al escritor caribeño que integra el bolero a la literatura desde la década de los sesenta como texto representativo de una comunidad. Benedict Anderson destaca cómo las novelas y los periódicos resultan un medio "for representing the kind of imagined community that is the nation” (25). Por tanto, sugiero al

\footnotetext{
${ }^{1}$ Para información general sobre bolero, origen, desarrollo, canciones y anécdotas, véanse Zavala; Rico Salazar; Restrepo; Orovio; Castillo Duque; Díaz; Loyola; Zapata. Los boleros citados se encuentran en Ayala; RicoFernández: “Tristezas”, 21; “Despedida”, 472; “Somos, 394; "Solamente una vez”, 336; “Caribe soy”, 387; “Diez minutos”, 28;1 Salazar “Soñar”, 350.
} 
bolero como texto cultural caribeño que facilita una indagación histórica del sujeto hispano-caribeño y de sus registros, tales como sus siglos fundacionales, su cartografía amorosa y el devenir regenerativo de sus naciones. Desde esta plataforma estudio Gestos (1963) de Severo Sarduy, Tres tristes tigres (1964) de Guillermo Cabrera Infante, Sólo cenizas hallarás (Bolero) (1980) de Pedro Vergés, La importancia de llamarse Daniel Santos (1988) de Luis Rafael Sánchez y La última noche que pasé contigo (1991) de Mayra Montero como textos que configuran una comunidad imaginada, distinguida, y soberana tras apropiarse del bolero para configurar política, erótica y escrituralmente al Caribe hispano.

VEREDA TROPICAL

Castillo Zapata en Fenomenología del bolero e Iris Zavala en Bolero: historia de un amor otorgan al bolero el frenesí y el desengaño con que el enamorado se desarma tras la voz, melodía, letra e interpelación desde la radio o desde la ansiedad que produce bailarlo en un solo ladrillo. Castillo Zapata declara que el bolero "posee la extraordinaria capacidad de servir de apoyo constante al enamorado hispanoamericano a la hora de elaborar las diversas peripecias que caracterizan su experiencia amorosa” (24). Zavala lo destaca como "texto cultural [que] transmite toda la cartografía amorosa hispanoamericana moderna; [...] la enciclopedia de las fantasías culturales sobre el amor” (67). Sí, efectivamente boleros como "Somos un sueño imposible”, “Tú me acostumbraste a todas esas cosas” y "Vereda tropical” son textos cuya autoría queda anulada tras la autorreferencialidad de la historia común porque el sujeto enamorado se siente enunciado en la canción. Tras la enunciación desfila la multiplicidad de sensaciones registradas por todo enamorado, desde la inefabilidad paradisiaca hasta el desengaño más provocador de cualquier acción. Este frenesí y subjetividad tan propio del Romanticismo se integra a los textos mencionados para documentar la poética amorosa del sujeto hispano-caribeño y así “cantar” las relaciones de poder entre los géneros.

En Gestos, Severo Sarduy metaforiza al género musical como texto cultural caribeño que canta los enfrentamientos y pasiones que eclosionan de los procesos nacionales e íntimos del sujeto cubano durante la década de 1950 y últimos años de la dictadura de Fulgencio Batista. La bolerista, actriz y mujer enamorada Dolores Rondón concilia la tragedia íntima y nacional tras integrarse a la lucha armada contra Batista debido a la muerte del amado. Doris Sommer afirma cómo la pasión erótica de la pareja heterosexual y la ideología política se concilian dentro de los sueños de prosperidad nacional haciendo de la pasión privada un propósito público. De tal modo, lo erótico y el bienestar nacional se concilian exitosamente y triunfa la ideología que permitirá la fundación ideal tras la pareja enamorada para representar el porvenir regenerativo de la nación (6-8). Tras esta correlación Sommer afirma: "to marry national destiny to personal passion was precisely what made their discipline’s books peculiarly American” (27). Aplicando y distanciando esta peculiaridad americana a Gestos, sugiero que para Dolores Rondón, este hombre representa su inscripción en la filosofía e integración a la lucha contra la dictadura de Batista. Derrotando al dictador se instauraría una movilidad para la prosperidad nacional 
y a su vez se celebraría la pasión erótica que los unió antes de su muerte. Así, la acción de amar al hombre por la patria o a la patria por el hombre se funde en sinonimia afectiva e ideológica en la alegoría de la pareja como fundación y regeneración de la nación. El distanciamiento dentro del siglo xx proviene de la deshonestidad con que el sujeto masculino concilia lo erótico y los proyectos nacionales. Él no es el héroe romántico cuya pasión homologa mujer y nación. Con su visión utilitaria se aprovecha de los sentimientos femeninos y del poco éxito de ella como bolerista y actriz para manipularla y convertir sus destrezas histriónicas a favor de su causa política y transformarla en terrorista. Ese es su gran papel. Así ella se consagra como actriz, bolerista y mujer enamorada.

La historia de Dolores Rondón replica la mímesis del tópico boleril que canta la pérdida de identidad del enamorado/a tras la adoptación de la identidad del amada/o. Ella, como la voz lírica del bolero “Toda una vida” del cubano Osvaldo Farrés, exaspera tal frenesí que se dispone a desaparecer y a reexistir mimetizando la filosofía de vida del “otro”. Allí, en el otro se registra la indemnización de sus carencias, permitiéndole a la enamorada celebrar la encarnación del enamorado sin cuestionar su propia desaparición. De este modo, Gestos, texto tan cubano como el bolero mismo en su origen, resulta el primer registro literario boleril, esa vereda tropical, en que convergen la problemática de género y la encrucijada nacional. Tal configuración emerge como plataforma primigenia que otros autores caribeños e hispanoamericanos superarán, otorgándole al bolero y a la cultura popular la capacidad de discurso político en la literatura.

¿NEGRA CONSENTIDA...?

Benítez Rojo señala en La isla que se repite que “cada raza y cada híbrido [...] bajo la bandera de su piel, porta [...] una historia local, una sociología y una economía que si bien diferentes y anacrónicas entre sí, presentan una turbulencia común” (218). Tres tristes tigres y su sección “Ella cantaba boleros” permiten esa auscultación de la piel tras la celebración de la aportación afrocubana a través de La Estrella Rodríguez, quien ficcionaliza la vida de la cantante cubana Fredy. ${ }^{2}$ El texto de Cabrera Infante así la convierte en fusión ontológica por encarnar a Cuba. Thomas Pavel define este concepto

\footnotetext{
${ }^{2}$ Aunque Cabrera Infante ya había escrito parte de los fragmentos que después constituyeron Tres tristes tigres, es la muerte de la bolerista Fredy lo que provoca la reunión de las partes en un texto. Según el autor, en entrevista con Álvarez Borland, la prohibición del documental P.M. lo preocupó, por lo que uniendo ambos motivos decidió "hacer P.M. por otros medios -y los únicos medios que [le] eran asequibles eran los medios literarios. Así surgió Tres tristes tigres, del cine y de la música popular" (63). Como lo indica su título, P.M. fue un breve documental sobre la vida nocturna y pública de La Habana en 1960 dirigido por el hermano de Guillermo Cabrera Infante. La Oficina de Censura de Cine, además de apropiarse del documental, prohibió su circulación por considerarlo contra la Revolución. Véase “Bites...”, Cabrera Infante 3-8. Respecto a Fredy, destaca Souza que ella había sido vista cantar por Cabrera Infante. Como La Estrella del texto, Fredy era la sirvienta de dos jóvenes profesionales que después se convirtieron en su víctima. También era la bolerista que se resistía a cantar con orquesta. Aunque no fue famosa, sí era conocida entre la comunidad nocturna habanera. Su muerte no ocurre en México como se ficcionaliza en el texto, sino en Puerto Rico en 1961.
} 
como "the establishment of a special relation of designation [...] which denotes the sacred object as manifesting the presence of the sacred, and [...] the adding of the note 'privileged, uncommon' to the usual attributes of the objects, on the profane level” (153). El histrionismo, el bolero y la muerte de La Estrella organizan el reclamo de esta auscultación de la piel para otorgarle la fusión ontológica y la sinonimia de Cuba. Códac lo privilegia al comentar las presentaciones de La Estrella, quien canta "sin música, quiero decir, sin orquesta, sin acompañante” (Cabrera Infante, Tres 50). Solo su voz y su mulatez logran efectos sin par de quien ni tan siquiera sabe leer música. Su canto reclama la autenticidad popular del bolero y destaca la aportación musical negra de cuyo cinquillo emergen el bolero y otros ritmos antillanos, mucho antes que éstos superaran su estado primario como creación popular mulata rechazada por las esferas dominantes, y se convirtieran en una reproducción aceptada por la cultura de masas tras la intervención del capitalismo. En diálogo con Gestos, el texto rememora las hazañas del trovador mulato cuyo espectáculo dependía de su virtual voz, de hacer su publicidad trazando cruces con tiza en las paredes y de reunirse en su comunidad donde la población mulata apreciaba su sencillez lírica. La Estrella inscribe la aportación negra en la perennidad nacional y continental bajo el estricto privilegio del texto de mantener el género auténtico siendo la única bolerista con las óptimas condiciones para difundir el bolero más allá de Cuba. Su gira artística a Puerto Rico y a México, países difusores del bolero después de Cuba, así lo consolidan.

Los dos finales de "Ella cantaba boleros" confirman la dimensión ontológica que busca la trascendencia de La Estrella. En el final de Tres tristes tigres, la bolerista muere y es enterrada en México. En La Habana, Códac, el fotógrafo de las estrellas que nunca la retratara, se preocupa por la inmortalidad de la diva: “en dos años ella estará olvidada y eso es lo más terrible, porque la única cosa por que siento odio mortal es el olvido” (217). Esta fusión ontológica -adjudicándole la distinción suprema que destaca Pavel- se reafirma en el segundo desenlace titulado “Metafinal”. Explícitamente La Estrella se confirma como sinonimia de la cultura popular cubana y como representante étnico fundador de la nación:

La cadena de evocaciones que llega a cada amante de la música del acento auténtico de Cuba, la lleva al público una voz de mujer, la de La Estrella. La Reina, la Monarca absoluta de la música cubana en todas sus manifestaciones. [...] en el alarde acentuado de una realidad indiscutida desde el ayer lejano al presente y, quizá en el futuro, hay una sola estrella. (18)

“Desde el ayer lejano al presente y, quizá en el futuro, hay una sola estrella” insinúa una evolución nacional que recrea la historia local señalada por Benítez Rojo tras la cultura de plantaciones en el Caribe y el zigzagueante presente dentro de la dictadura de Batista y el augurio de la revolución castrista. Dentro del presente y el futuro, Códac enuncia un epitafio tan equivalente para La Estrella, como para Cuba: "Sicus Vita Finis Ita. Solo que realmente pronuncié Si Cubita Finisita” (22). Dentro del ayer La Estrella, como miembro de una población fundacional, reclama la aportación cultural afrocubana a través de una de las manifestaciones de mayor registro sociológico y prolijidad, la música. Esta también se celebra en Tres tristes tigres mediante el homenaje de Eribó al mulato Benny Moré, 
quien como performer de la música afrocubana, testimonia la connotación peyorativa que la cultura dominante adjudicó a toda producción artística de origen africano. ${ }^{3}$ Así, la política discriminatoria hacia un color no oficializado se refracta un siglo después. A cambio se proyecta desde el escenario un encuentro e intercambio con el "otro" demostrando la recepción de los signos culturales mediante la aprehensión e incorporación de éstos en las culturas dominantes. Esta presencia denota una movilidad pública dentro de la reapreciación cultural adjudicada al transformarse las historias locales.

Como destaca Helio Orovio "el bolero constituye [...] la primera gran síntesis vocal de la música cubana que al traspasar fronteras registra permanencia universal” (50). La Estrella -“mulata gorda, gorda” (219)- obra como la monoestrellada bandera nacional cubana. Su notoria figura barroca desde el escenario proyecta el origen primigenio del bolero y a Cuba como cuna de su invención. También proyecta el sincretismo y cambio de los signos culturales, junto a la incertidumbre del presente y del futuro nacional. De este modo, el bolero se registra como texto cultural literario al permitir la auscultación de la historia nacional cubana.

Esta historia nacional cubana se especifica cuando el bolero problematiza la relación entre los géneros y diversifica la función utilitaria de la mujer que convierte a la Dolores Rondón de Gestos en víctima. El texto de Cabrera Infante así cuestiona las circunstancias socio-culturales y raciales de la mujer en su relación con el bolero, con el espacio público y con la jerarquía patriarcal en “Ella cantaba boleros”. Michelle Zimbalist Rosaldo afirma que "in every human culture, women are, in some way subordinate to men. [...] Women may be important, powerful, and influential, but it seems that, relative to men of their age and social status, women everywhere lack generally recognized and culturally valued authority" (17). Códac, "tigre” que narra "Ella cantaba boleros”, patentiza la asimetría social que deviene de la actividad desempeñada por ambos sexos en el espacio público del cabaré. Aquí se escenifica la legitimidad, autoridad y estratificación. Mientras la bolerista -con excepción de La Estrella- es identificada como vedette, al sujeto masculino se le destaca como dueño de este espacio por excelencia. La representación de la vedette Cuba Venegas y del ambiente cabaretero muestran las implicaciones culturales:

Y me zambullo en la música y en el ruido de los vasos y en el olor del alcohol y humo y el sudor y en las luces de colores y en la gente y oigo el famoso final de ese bolero que dice, Luces, copas y besos, la noche de amor terminó, Adiós, adiós, adiós, que es el tema musical de Cuba Venegas y veo que ella saluda elegante y bella y toda de azul celeste de arriba abajo y vuelve a saludar y muestra los grandes medios senos redondos que son como las tapas de unas ollas maravillosas que cocinan el único alimento que hace a los hombres dioses, la ambrosía del sexo, y me alegro que esté saludando, sonriendo, moviendo su cuerpo increíble y echando atrás su hermosa cabeza y que no esté cantando porque es mejor, mucho mejor ver a Cuba que oírla y es mejor porque quien la ve la ama, pero quien la oye y la escucha y la conoce ya no puede amarla, nunca. (211)

\footnotetext{
${ }^{3}$ Consúltese esta baja estimación del afrocubano en La música en Cuba de Carpentier 136. Para información sobre Benny Moré véanse Orovio 253.
} 
Tal retrato en movimiento provoca estratégicamente la recreación de otra existencia apelativa a los sentidos y a las apetencias de sus clientes. Cuba Venegas no es más que otro dispositivo recreativo que confina a la mujer tras presentarla como un objeto generador de placeres y entretenimiento dentro de la política sexual masculina. La Venegas no es admirada por su canto, sino por "los grandes senos [...] las tapas de unas ollas maravillosas que cocinan el alimento que hace a los hombres dioses” (211).

El bolero, su cuerpo y carisma obran del tal forma que devalúan sus potencialidades y le otorgan el aprecio que pudieran tener otros dispositivos que causan la recreación del deseo masculino. De esta manera, se iguala el espacio público del cabaré con el espacio privado del hogar, donde el hombre tiene a su esposa para que le cocine y le ofrezca "la ambrosía del sexo”. Cuba Venegas concilia esta sinonimia con la mujer hogareña inscribiéndose dentro de la misma función sexual utilitaria, ya que también es juzgada según sus acciones satisfagan o no las necesidades masculinas. Por tanto, el bolero no se presenta como cultura del “pueblo”, sino como emblema de la estratificación y diferenciación de los sexos que oficializan las actividades que denigran la proyección de la mujer sin importar el espacio. Cuba Venegas, sin meditar la configuración femenina que consolida, es codificada sobre el escenario como una atracción erótica exitosa. Culturalmente, ha sido condicionada para que su acto boleril obre como el principal recurso que minimiza la marginalidad. Su auto-cosificación la convierte en deseante de un espacio y en deseada para un fin, sin procesar que la evolución de la guajira Gloria Pérez a la vedette reproduce una falsa conciencia femenina. Celia Amorós destaca que "el oprimido parece estar condenado a no saber de sí mismo sino bajo la forma de la falsa conciencia. [...Esta] es la complicidad más eficaz y profunda que puede encontrar un sistema de dominación” (72). La falsa conciencia de Cuba no se origina desde su centro, sino desde la perspectiva del hombre. Así el sistema se organiza y disuelve el potencial del sujeto femenino cuando lo crea a semejanza de su voz, pero permitiéndole una supuesta movilidad que lo encauza en la constante circularidad de su principio: una estratificación devaluada.

Como destacara antes, el cuerpo mulato se asocia con la música en Tres tristes tigres; no obstante, la celebración de la herencia africana que encarnan La Estrella y Benny Moré contrasta con la establecida entre bolero, mulatez y vedette. El texto polemiza la apreciación socio-cultural de la mulata al identificarla como objeto sexual de fácil alcance. Los “tigres” divulgan que Ingrid “es una mulatica muy adelantada [...] y es bastante fácil” (122), mientras que Cuba Venegas luce “más alta, más bella y más puta que nunca” (20). Dentro de esa sociología y polémica de la piel, puede afirmarse que esta actitud mancilladora deviene de esa "historia local" que resguarda culturalmente registros de la esclavitud. ${ }^{4}$ Primero esta "historia local” trae consigo un pasado de mujer esclava en las

4 Verena Stolcke documenta en Racismo y sexualidad en la Cuba colonial expresiones populares en boca de hombres blancos que enuncian toda una política discriminatoria hacia la mulata. Expresiones como: "aunque parda vivía honestamente" o "no hay tamarindo dulce ni mulata señorita” (181), consolidan culturalmente unas expectativas de la moral pública de la mulata al presentarla como mujeres de frágil moral sexual. Consúltese el poema "Mujer negra” de Nancy Morejón, el cual relata esta "historia local" que se porta tras el color de la piel. El yo poético del poema devela la presencia clave de la mujer negra en la fundación, colonización, independencia e incursión en el socialismo del pueblo cubano. Véase también Cámara. 
plantaciones de los colonos donde la relación de poder las identifica como víctimas de las apetencias y violaciones de sus amos. Segundo, como producto de esa relación de poder, nace un sujeto mulato y bastardo cuyo color y fisonomía no resultan institucionalizados. Finalmente, tras esa negación de la oficialidad de su piel y de sus rasgos africanos emerge un deseo de blanqueamiento debido a que su cuerpo y su estigma social enfrentan los prejuicios de todas las organizaciones de poder. Por tanto, ser mulata implica una doble devaluación: la que culturalmente se le otorga por su condición natural de ser mujer, y la que porta su "historia local" como sujeto poseído de múltiples formas por el sujeto opresor. Irene y Cuba son las réplicas de Cecilia Valdés cuya historia local las acusa de los múltiples usos y deleites que provocó su piel, subrayando su aparente disponibilidad, su encanto como objeto sexual y el escaso respeto social en el siglo xx.

Es importante clarificar la diglósica postura del bolero como texto cultural que socava al sujeto femenino cuando precisamente se alegoriza a Cuba a través de La Estrella. La consagración de Códac reconstruye la dimensión ontológica que ésta encarna tras su muerte al adjudicarle el don de lo privilegiado y excepcional. Las demás boleristas -como los "tigres", quienes narran y estratifican- no rebasan su estado cotidiano. No obstante, este privilegio solo se logra tras la muerte si el sujeto ha sido un ser excepcional como La Estrella. Su excepcionalidad no emerge solamente de su sinonimia con la nación, sino por ser quien refracta la falsa conciencia que impone el patriarcado a la mujer ya que La Estrella no cumple las expectativas ni las condiciones de ser una mujer a la imagen, semejanza y necesidad masculina. Su cuerpo no es el apetecible cuerpo de Cuba Venegas, sino la contraoferta que no impacienta la libido. Y aunque La Estrella sí tiene talento, su carácter inmanipulable, su falta de carisma y su ordinariez la presentan como lo temerario y lo extraño. Comportándose así en y fuera del escenario resulta la antinomia de Cuba Venegas para demostrar que la apropiación del bolero en la literatura se inscribe en la pluralidad. Por un lado, evidencia que el bolero no es solo un discurso masculino que puede construir una esperada cosificación erótica de la mujer del cabaré, o que puede obrar como un contradiscuro desmantelador de la falsa conciencia y autoridad de la sociedad patriarcal. Su excepcionalidad ofrece la dualidad de burlar o ser burlada desde la misma tribuna pública del escenario.

Al contrastar las actividades que otorgan prestigio o marginalidad en Tres tristes tigres, la autoconciencia y la intelectualidad emergen como dones otorgados a los hombres. Mientras Cuba Venegas sonríe, saluda y se mueve, Silvestre destaca que "viajar con Cué es hablar, pensar, asociar” (223). Como bien apunta Susan McClary: “a man skilled in oratory was powerful, effective in imposing his will in society at large” (38). Aún estando sobrios o ebrios el don de la elocuencia fluye en Silvestre y Arsenio Cué mientras dan su viaje por el Malecón. Con el poder de la palabra ellos hacen alusiones literarias universales, anteponen la literatura aleatoria a la tradicional, debaten de música, de filosofía y de otras áreas de la humanidades, tienen la responsabilidad y el honor de recopilar todos los subuniversos de la cubanidad, vetan la política de Batista y crean sospechas del futuro con Castro. Además, mediante la palabra, se les otorga la encomienda de refrenar el apocalipsis de la cubanidad a través de la rememoración de la nación. Evidentemente, la retórica y las otras actividades de trascendencia, proponen a la intelectualidad y a la alta cultura como don exclusivo del hombre, mientras la retórica del 
bolero solo enuncia a la mujer dentro de su capacidad seductora o de ser espectáculo ya sea por su calidad sensual o de burla. Como afirma Michelle Rosaldo respecto a la cultura patriarcal: "men are the locus of cultural value" (20). Por tanto, el sujeto masculino aprende desde niño a alejarse de las actividades en que incurre la mujer en el hogar para involucrarse en otras actividades que les permitan el prestigio social. Así, demuestran que la cultura emana desde sus hemisferios públicos y no desde los espacios y actividades concedidos a la mujer, práctica construida que se puede asumir libre de todo cuestionamiento.

Celia Amorós - al estudiar los postulados de Hegel- destaca esta práctica como eticidad, la cual "se relaciona con el conjunto de hábitos y ethos característicos de un determinado pueblo, que constituyen una segunda naturaleza” (42). De modo que el espíritu ético organiza una específica construcción de la cultura. El establecimiento de esa "naturaleza” tanto esperada del hombre como de la mujer implicaría una diferenciación aceptada culturalmente de la política pública y privada de los sexos. Tres tristes tigres, a pesar de la excepcionalidad de La Estrella, se inscribe como texto cultural que documenta la problemática de los géneros dentro de la vida cotidiana. Como se demuestra, las actividades en que el hombre incurre le permite organizar grupos, estructurar el poder y diferenciar la masculinidad más allá del cuerpo mediante una jerarquía bipolar: hombre, legitimidad y autoridad contra mujer, subordinación y utilidad. En voz de los "tigres": "Códac deseando que todas las mujeres tuvieran una sola vagina (aunque él no dijera exactamente vagina) o de Eribó erigiéndose en el sentido que camina o el difunto Bustrófedon que quiso ser el lenguaje. Eramos totalitarios: queríamos la sabiduría total, la felicidad, ser inmortales al unir el fin con el principio” (240).

Y SI PRETENDES REMOVER LAS RUINAS

Sólo cenizas hallarás (Bolero) retoma su título del bolero “Cenizas” de Wello Rivas para cantar metafóricamente el cataclismo de la nación dominicana tras los treinta y un años de dictadura de Rafael Leonidas Trujillo y su asesinato. Como restaurar el país se convierte en asunto de hombres, la mujer irrumpe en el romance para contrarrestar la convulsión cívica y el estancamiento social y así satisfacer su necesidad íntima desde el mismo espacio confinatorio del hogar. Allí se recibe la educación sentimental del programa radial Yo canto para ti, de la Novela Colgate-Palmolive, y sobre todo del bolero. Esa gala de imaginaciones y sonidos les permite canjear “el país de mierda, país de gente bruta, país maldito” por la imagen de los castillos, príncipes azules y vida glamorosa (352).

La pluralidad del bolero amplía sus registros de interpelación cuando la música popular también emerge como dispositivo sexual y devela la relación entre parejas del sujeto caribeño. Zavala expresa que "la música popular emerge como una máquina antiopresiva: [es] el discurso del otro y de la otredad seductora que libera el cuerpo” (17). La seducción de la voz del cantante, la autorreferencialidad de la letra, el naufragio personal, la insistencia coral y rítmica, y posiblemente el contacto físico con el Otro transforman a la música en esa "máquina anti-opresiva”. La conjunción de estos recursos trae consigo el paroxismo de los placeres corporales, un deseo recurrente del Otro, una enajenación de la problemática social y la erosión de la política cultural sexual. Desde su naufragio personal, Yolanda y Lucila asocian respectivamente al bolero "Vereda tropical” y a los 
bailes de merengue con el despertar sexual de sus cuerpos. Ellas otorgan una ideología a la música popular caribeña: la de liberación y deleite del cuerpo, y la de liberación de las regulaciones culturales respecto a la sexualidad femenina. Así, Yolanda disfruta su bolero con Carmelo y termina “jadeando como loca, abriendo piernas y cerrando piernas” (24), mientras Lucila "iba al queme de cualquier verbena a bailar su merengue chochito con bimbín” (169).

El sujeto masculino se aprovecha de esta apertura y usa a la mujer como artificio recreativo. Ellos recodifican la música popular caribeña como lenguaje embaucador del amor y del sexo y fraguan la caída de la mujer que se ha liberado de las ideologías represoras. Tal planteamiento no implica una correspondencia de deseos entre los sexos, sino un contraste abismal de cómo cada género codifica el registro musical. Ellas llegan al acto sexual después de que ese bolero en voz de sus respectivas parejas ha obrado, y más allá de esa liberación del cuerpo, también se ha operado un despertar de los sentimientos. Desde su registro, cuerpo, música y sentimientos permiten la experiencia sexual como anticipo de un imaginario de felicidad ante la llegada del príncipe azul. Mientras ellas aspiran al matrimonio y al disfrute de la pasión conyugal, ellos dan por terminado el bolero cuando el cuerpo femenino es poseído. Como los conquistadores, una vez ejecutada la conquista, ellos proceden al saqueo y después al abandono. Así, el texto desde una plataforma patriarcal, problematiza la pérdida de la virginidad como consecuencia de la liberación que produjo la música caribeña y del embaucamiento masculino. Culturalmente se etiqueta como devaluada a la mujer que transgrede los aparatos formadores en que se está inscrito desde la infancia sin cuestionar las ideologías de la familia, el credo religioso, las tradiciones y costumbres sociales.

Como declara Althusser, "an individual is always-already a subject, even before he is born” (176). Estos aparatos formadores se constituyen generacionalmente ya que no existe sujeto fuera de o anterior a la interpelación ideológica. Él recibe registros que indican su pertenencia y membresía a un grupo y no al otro. Los sujetos que polemizan la virginidad en Sólo cenizas hallarás asimilan una moral sexual que celebra y demanda la castidad de la mujer soltera porque ésta genera el honor familiar y la proyección futura de la mujer soltera que practica o transgrede el ideal de la pureza. El rechazo de Wilson a Yolanda por perder su virginidad en Nueva York antes de su noviazgo se basa en las ideas culturales de la sexualidad dominicana y de su clase burguesa. Por tanto, la polémica entre lo erótico-nacional y lo erótico-económico anticipa el destino de la pareja. Sommer plantea la existencia metonímica entre la pasión y el patriotismo destacando la "association between romantic love that needs blessing and political legitimacy that needs to be founded on love” (41). Wilson tilda de prostitución "la pérdida de la virginidad como consecuencia de [la] libertad sexual que se practica en las grandes ciudades de los países industrializados” y proyecta la carga nacional con que el país organiza la moral sexual de las parejas para tener esa bendición y legitimidad política (162). Tal rechazo demuestra el valor que la sociedad patriarcal otorga a la pérdida de la virginidad dentro del espacio local, y al valor que la burguesía concede a quien aspira a ascender socialmente sin los méritos de su clase. Antes de conocer la aventura boleril de Yolanda, Wilson desciende y se relaciona con una mujer de clase media, pero el conocimiento de la verdad paraliza mayor movilidad. Beatriz Sarlo destaca que "la caída es la figuración moral del obstáculo 
social o económico. [...] Siendo pobre, la joven estaba afectada por una carencia; entregándose agrega a esta falta otra” (114). La aceptación de tales faltas lanzaría a Wilson a la tribuna pública para ser juzgado por los miembros de la colectividad patriarcal y burguesa a la que pertenece.

Ante la carencia de otros recursos para expresar su titubeo, el bolero "Te odio y te quiero” emerge en la voz de Wilson como lenguaje reproductor de sus sentimientos. O Wilson se reafirma dentro de una cultura patriarcal-burguesa que demanda la virginidad como valor irremplazable o reconstruye sus códigos. Ante la carencia de registro cultural que promueva la movilidad de la moral sexual, el sujeto se acoge a la ideología existente ya que le resulta incuestionable y compartida por los de su mundo. De esta manera, pasión, patriotismo y legitimidad nacional van de la mano tras la reafirmación de lo aprehendido. Wilson socava la diferencia cultural de lo que él llama "los países industrializados" respecto al sexo desde su representación cultural y clase social. El bolero como texto que registra las relaciones de poder devela cómo la cultura popular puede tanto apoyar los registros patriarcales como motivar esas transgresiones que demuestran la invalidez de esas aprehensiones.

Yo NO HE VISTO A LINDA

La importancia de llamarse Daniel Santos de Luis Rafael Sánchez en diálogo con Tres tristes tigres y Sólo cenizas hallarás (Bolero) ausculta esta configuración que presenta al bolero como un discurso monológico al servicio del patriarcado. El texto destaca al bolerista Daniel Santos como mítico semental caribeño cuya duplicidad desean los hombres y cuya presencia lacera a las mujeres tras "bailar un bolero que canta Danielito” (178). La segunda parte, “Vivir en varón”, propone a la familia como el origen de la representación cultural que fomenta la poética y réplica de vivir en varón:

El consuelo de un varón completo de quince, dieciséis, diecisiete años es [...] fumar cigarrillo o pasto, pasarse horas en los billares. [...] Otro consuelo es escuchar al Pai mascullar Ya ese muchacho emplumó, Ya ese muchacho mea dulce. Otro consuelo es escuchar a la Mai cacarear La que tenga hija señorita que la amarre. Que mi cachorro está suelto por la calle. (83)

Rosaldo destaca que "the boy must break away from his mother and establish his maleness as a thing apart. [...] he is apt to be restless and assertive and to seek out horizontal ties with male peers” (25). Actividades contrarias para el varón como el gozar más de los espacios públicos tras disasociarse de la madre y sus hermanas, intercambiarían el éxito por el fracaso, y lo expondrían a una conducta afeminada o endeble por privarle de la calle y de la influencia de sus amigos. Desde el hogar, la interpelación cultural muestra al patriarca y a la matriarca en su regocijo ante la “machería” de su vástago. La explosión de su virilidad y las actividades en el espacio público garantizan y perpetúan la conducta hegemónica de lo que ser “macho” implica. Así se fecundizan los atributos ideales para la representación del varón mediante los cuales el padre perpetúa una mentalidad inamovible y se prolonga como sujeto dominante y semental en su hijo. En cambio, la 
madre fija su orgullo en la amenaza pública y animal del “cachorro” por “vivir en varón” y no en la promoción de sujetos masculinos alternos. Como réplica cultural, ella no conoce la inmovilidad social ni femenina en la cual fue criada y contribuye a perpetuarla. Solo manifiesta que para el óptimo desarrollo de su “cachorro” resulta imperante la subordinación y la cosificación de la mujer.

Esta política monológica muestra su temores tras sus padres preocuparse tanto por el comportamiento del "cachorro" según las expectativas culturales. Frances Aparicio, señala que "the ambiguity of this performance is linguistically constructed in the anaphoric patterns of the phrase parecer varón [...], an utterance that signifies both machismo as performance and an articulation of homosexuality as a histrionic act” (141). Por tanto, vivir en varón y parecerlo implica una pluralidad sexual dentro de la masculinad y no precisamente una relación directa con la heterosexualidad.

Desde ese mismo centro eclosiona la disidencia a través de la preferencia homosexual pero registrando histriónicamente la hegemonía de género cultural aprehendida. Así la política dominante sufre su destitución y a cambio se efectúa una explosión del sujeto en toda su pluralidad. ¿Cómo entender entonces la teatralidad que incauta al sujeto disidente del closet cuyo modelo masculino es el bolerista Daniel Santos? Eve Kosofsky Sedgwick afirma que "gay thinkers of this century have never been blind to the damaging contradictions of this compromised methaphor of in and out of the privacy" (72). También observa que la incautación en el closet es el rasgo fundamental y formador del estilo de vida homosexual (68-9). ¿Por qué se suscita entonces la poética de "vivir en varón” dentro del armario emulando al bolerista Santos? Dentro de un cultura patriarcal, el sujeto disidente de esos registros se atemoriza del conocimiento público de su diferencia. Él y su mundo inmediato desconocen y podrían tergiversar la razón de su disidencia sexual ya que ellos son seguidores de un dominio filosófico popular y de unas instituciones que oficializan la hegemonía sexual. El sujeto del closet como miembro de esa cultura, solo se protege de la homofobia que su preferencia sexual podría causar. Desde su niñez, éste es testigo de los ataques e incomprensiones que se suscitan desde su hogar, iglesia, escuela, actividades sociales y laborales. Por tanto, el closet se convierte en el espacio desde donde se evita el enfrentamiento y la discriminación de estas instituciones.

Para quienes glorifican el donjuanismo de Daniel Santos y el arte del apalabramiento del bolero, la salida del closet sería un acontecimiento público alarmante. Desde su hegemonía sexual, ellos enfilarían sus cañones contra un erotismo repudiado y patológico. Ante la opresión pública, el macho del closet sube al escenario y replica la virilidad del “cachorro” heterosexual. Sin embargo, desde allí ejecuta su bolero a través de otra lírica. Su escondite es la voz dialógica de lo contrario, ambiguo y aparentemente mandatorio que resulta la heterosexualidad. Dentro de las historias de Santos, el mítico semental, la dialogía de la masculinidad sería una transgresión impropia para bolerarse públicamente por la "incorrespondencia” de géneros para la cual el yo cantor expresa tradicionalmente sus afectos y deseos amorosos.

¿Cuál es la verdadera importancia de llamarse Daniel Santos desde la problemática de la masculinidad? El texto de Sánchez fragua la virtual y popular concepción de la masculinidad - del machismo caribeño como modelo cultural a través de la figura arrolladora de Daniel Santos y del espacio del hogar que lo gesta. Como bolerista, la 
celebridad y la fanaticada arman las propiedades a emular por todo aquel aspirante a “macho". Así, el bolero se presenta también como discurso de férrea crítica de la masculinidad magnánima y poco progresista que culturalmente reproduce. Su crítica se fundamenta en dilucidar los artificios para doblegar con pasión, deseo y a veces con violencia al sujeto femenino a través de la virilidad, el poder, la fama y la capacidad seductora. Como demuestra Sánchez, este "bolero" de masculinidad sufre sus reduplicaciones y permite el enfrentamiento que desmitifica esa verdad dominante mediante la preferencia sexual de un sujeto de su mismo sexo. Desde su misma base cultural machista, el sujeto del closet crea su transgresión sin mostrar esa preferencia que ocasionaría perturbaciones públicas para todos los sectores. Si bien es cierto que el espacio del "closet” no le permite la absoluta oficialidad de su sexualidad, sí organiza una liberación paulatina que presenta otra visión de la masculinidad y del bolero como refundidor de códigos culturales.

Somos DOS GOTAS DE LLANTO EN UNA CANCIÓN

Como lo anuncia el título y confirma el índice, La última noche que pasé contigo de Mayra Montero resulta el texto que más explícitamente se apropia del bolero y de la cultura popular como discurso intertextual para preludiar las tempestuosas relaciones de amor y desengaño que encarna el sujeto caribeño tras la interpelación del bolero. Canciones como "Sabor a mí”, "Negra consentida”, "Somos”, entre otros, circularon diferentes historias de amor que en el texto guardan correspondencias con las pasiones desenfrenadas de los personajes durante su crucero por el Caribe. Isla tras isla, Fernando y Celia certifican cómo el bolero obra como discurso propulsor de sus relaciones amorosas dentro y fuera de su matrimonio. Como enuncia Celia, "bailar en un sólo ladrillo”, “cortarse las venas” y "hacerse polvo” son los apasionados efectos que violenta la canción tras el enamorado reconocer su autorreferencialidad en la historia pasional cantada (88). Por tanto, el bolero se configura como sinonimia erótica y concupiscente que circula la pluralidad de los placeres dionisíacos e incita el deseo por el “otro”. ¿Implica ese contacto con el “otro” la réplica solo de las prácticas heterosexuales y la turbulencia erótica de Celia y Fernando? No precisamente. Como anticipa La importancia, el bolero también es apropiado por el sujeto transgresor de la sexualidad binaria.

Rosemary J. Coombe documenta cómo los grupos de sexualidades marginadas se acogen a la cultura popular y a las celebridades que la representa para crear subculturas. Dentro del proceso emerge la reproducción de “otra” sexualidad y no de las formas dominantes. Según Coombe "cultural consumption is increasingly understood as an active use rather than a passive dependence upon dominant forms of signification” (113). Tal implicación advierte sobre las prácticas y negociaciones incurridas tras el acto de consumo de la cultura popular. Así, su receptor convierte el acto pasivo en producción cuando recodifica los registros recibidos y los adapta y satisface sus propios intereses. Entre estos intereses, figura la creación de nuevas propuestas de géneros que subvierten las formas dominantes ya que el binarismo tradicional no los representa (112-5). El bolero, entonces, se convierte en un dispositivo de sublevación erótica, permitiendo la emersión del 
lesbianismo. Fernando, quien de niño funge como el celestino de su abuela Ángela y de su amante Marina (Abel), lo enuncia:

\begin{abstract}
$\mathrm{Al}$ cabo de un rato, si el abuelo estaba fuera de la casa, las dos mujeres se levantaban y se iban derecho al cuartito de escuchar la música. La abuela ponía un disco, "una vez nada más en mi huerto brilló la esperanza”, y, cuando yo intentaba entrar, pasaba el pestillo, me gritaba desde dentro que las dejara quietas [...] cuando terminaba la música, "hay campanas de fiestas que cantan en el corazón”. [...] Eran veladas musicales que se prolongaban hasta las diez, a veces hasta la media noche. (180-1)
\end{abstract}

La referencia al bolero "Solamente una vez” de Agustín Lara se sugiere como el espacio vital de ellas ya que resulta su pretexto de reunión, la celebración de sus líbidos y la consumación de un deseo común. Desde la existencia de Ángela, “una vez en mi huerto brilló la esperanza” implica la transgresión de las prácticas propias del patriarcado que delimita su preferencia sexual ya que vivió una heterosexualidad disfrazada. Por tanto las “campanas de fiestas que cantan en el corazón”, esa velada musical, representa su vivencia, deseo y autorreferencialidad en códigos que declaran su propia autonomía y paroxismo después del acto de consumo y producción tras desmantelar el binarismo sexual.

Dentro de las configuraciones del bolero, la pluralidad no tan solo libera al cuerpo y permite el frenesí, también resguarda su atentado contra la felicidad y resume la pena. El bolero "Somos" resulta el canto elegíaco que recopila la celebración y la tragedia que conjugan a Ángela y Marina otoñal después que se separan. Tal es el paroxismo -según Celia- que "hubo que ponérsela [la canción a la abuela] diecisiete veces antes de que entrara en coma” (183). La vida de Ángela resulta un encadenamiento de boleros: replica una sexualidad no correspondida desempeñándose como la mujer típica, después invierte la represión en la vitalidad paradisíaca, finalmente quien glorifica sus deseos la abandona por otra. ¿Por qué tal paroxismo previo a su finitud? Porque "Somos” reproduce y sintetiza la relación de las amantes que "Solamente una vez” permitió explorar:

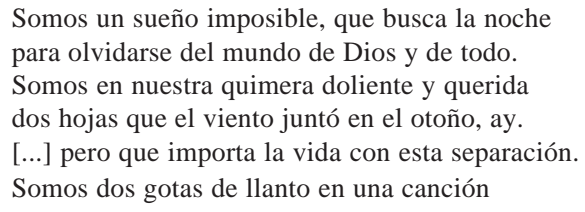

La conjugación plural del verbo "ser" por la otoñal pareja en "somos" implica la reunión de la misma disidencia, la transgresión de la existencia cotidiana cuando la resignada heterosexualidad había tomado por costumbre a Ángela. Georges Bataille destaca que "el gusto por el cambio es sin duda enfermizo, y sin duda no conduce más que a la frustración renovada” (155). Dentro de su tragedia, el estado moribundo de la abuela Ángela y la insistencia de escuchar diecisiete veces el bolero dramatiza y mantiene vigente la tardía plenitud brindada por Marina, demostrando cómo la carencia de lo vital y el abandono desarticulan al sujeto cuya felicidad resulta ahora solo materia boleril. Esta 
recepción también encarna el lamento de su separación y el reconocimiento de que la felicidad experimentada no es cíclica, como sí lo es su lamento. Sin embargo, la petición del bolero que canta y resume su pasión reorganiza el registro de los placeres. Ángela tiene como mérito póstumo la abolición de las regularidades tras la vivencia de su pasión. Estos boleros no son tan sólo su autobiografía amorosa, sino que fraguan el atentado mediante un lenguaje reproductor de otra experiencia amorosa que les ofrece un desquite contra quienes prohíben la manifestación de su deseo. Como afirma Foucault: "quien usa ese lenguaje hasta cierto punto se coloca fuera del poder, [...] anticipa, aunque fuera poco, la libertad futura” (25). Dentro, su producción, tanto para Ángela como para las ya mencionadas La Estrella y Yolanda, la manifestación de sus códigos figuran como victoria trascendental. Disolver la hegemonía sexual continúa siendo un supremo desafío con mayores consecuencias, pero es un paso vital que identifica a quien se va colocando fuera del poder.

Vengo A DECIRLES Adios A LOS MUCHACHOS...

La importancia de llamarse Daniel Santos junto a La última noche que pasé contigo rebasan la frontera oceanográfica con la intención de crear una propuesta más allá de los puntos cardinales de un país específico. En La última noche la ebullición erótica se moviliza al compás musical del bolero según navega el crucero por el Mar Caribe. Su indagación de la práctica heterosexual y homosexual demuestra la convulsión del sujeto en la manifestación de la diferencia y en la movilidad sexual caribeña. En este sentido, el viaje de Celia y Fernando, dentro de su intención de retratar al Caribe como la postal o el afiche turístico seductor, también invita al turista a sumergirse en la aventura que siempre imaginó pero que no realizó por las regulaciones sicológicas o culturales. Mito o realidad, el Caribe es delineado como un espacio de efervescencia erótica plural a pesar de las organizaciones que intentan regularizar la sexualidad y el bolero como un aliado que perturba y motiva la realización de fantasías eróticas. La ruptura de la colindancia nacional en La importancia mediante su viaje por “la América en español” le permite a Luis Rafael Sánchez -viajero y personaje en su texto-presentar una propuesta complementaria a la de Montero, pero formulando una identidad continental partiendo desde el Caribe (Sánchez 131). De este modo, escribir una hagiografía laica del bolerista puertorriqueño Daniel Santos se convierte en un pretexto para delinear la homogeneidad de Hispanoamérica como nación-continente.

Según James Clifford viajar es una "institutionalized activity, inviting historical specification” (183). Sánchez así lo evidencia en búsqueda de una coyuntura histórica que devele al sujeto hispanoamericano y crea un imaginario del Caribe y de la "América en español” durante su recorrido (131). La respuesta a la pregunta de Clifford -“what kinds of knowledges, stories, and theories do they produce?”- resulta su agenda vital mientras el viajero supuestamente recopila testimonios sobre Daniel Santos (Clifford 183). Así, el bolero y el bolerista fungen como metáfora documental del continente. Desde Lima, el investigador y viajero celebra la etnicidad caribeña cuando Sin Papeles personaje femenino que se encuentra con el bolerista- pregunta "si tanto hombre portaba sangre de Atahualpa”, comentario contestado por Santos “con antillanía implacable [...] 
que tanto hombre portaba todas las sangres. Del taíno Agüeybaná el Bravo. De la mocita Tembamdumba. De Las Quimbambas. De algún españolete del decir metaforoso” (30). La respuesta de Santos trae consigo toda una carga histórica y fundacional del Caribe al presentar como modelo virtual al sujeto mestizo. A pesar de que el indio taíno, el esclavo africano y el amo español recuerdan las prácticas fundacionales de colonización -tras la sanación de los actos de violencia-se establece y se ensalza la hibridez étnica que le otorga esa majestuosidad antillana u otra majestuosidad dependiendo la conjunción racial de otro espacio geográfico. Como enfatiza Ernest Renan respecto a los procesos evolutivos de las naciones, desde esa práctica de sanación se proyecta el indeleble pasado histórico con la esperanza de dirigirse hacia un futuro reconstructor (19-20).

Además de las prácticas fundacionales, Sánchez testimonia la repetición histórica de la tragedia política continental del siglo xix en el xx. A través del "testimonio de una mujer añosa en un refugio católico de mi viejo San Juan” (13), Daniel Santos se convierte en autorreferencialidad del bolero "Despedida” de Pedro Flores tras el reclutamiento de los puertorriqueños que luchan en la Segunda Guerra Mundial para defender a la otra patria, la norteamericana. De este modo, la mención de Daniel y del bolero que canta el abandono de la madre, la novia y la patria desposeída devela la situación histórica neocolonial de Puerto Rico cuyo destino político guarda correspondencia con otros países hispanoamericanos. Así, el bolero y la convulsión nacional permiten el diálogo entre Tres tristes tigres, Sólo cenizas hallarás y La importancia.

La importancia de llamarse Daniel Santos y Sólo cenizas hallarás presentan a la República Dominicana como la nación desmantelada tras la dictadura de Trujillo. Persio Almonte, cuyos “ojos vieron la ascensión y la caída de LA BESTIA” (Vergés 55), lo confirma:

Cementerio sin cruces fue este país desde que se lo apropió la BESTIA [...] Mucha fue la gente buena que se fue. Mucha fue la gente buena que se quedó en República Dominicana sin empuercarse y mal vivió. Lo que LA BESTIA mató no tiene madre. Mató las confianzas. Mató los reposos de la noche. (56)

Persio Almonte como doble de doña Altagracia en Sólo cenizas hallarás enuncia los problemas de emigración, la desconfianza política, el subdesarrollo nacional, y coincide en la especificación histórica y revisión introspectiva tras la dictadura de Trujillo. Su voz no ausculta la derrota, sino que refleja la turbulencia del presente y hace elocuente la urgencia de la paz aun después de la desaparición del dictador pero no de los remanentes de su dictadura. Por tanto, llamarse Persio o Altagracia -como la virgen patronal dominicana-resulta patentizar la comunidad mediante la voz del pueblo y de su memoria colectiva. El dúo enuncia la imposible liberación del pasado dentro del presente, la violencia durante la dictadura, la inmovilidad de las clases sociales, la turbulencia económica y los problemas para lograr la modernidad. Como destaca Fernando Valerio Holguín "el bolero tiene como función la organización de una temporalidad que remite a la historia” (198). Tras la organización temporal simultánea, el bolero acude como testigo y pretexto para la especificación histórica. Sánchez solo motiva la conversación de las visitas de Daniel Santos a La República durante la dictadura y fluye la elocuencia de 
Persio. Altagracia, por su parte, oblitera el dolor escuchando danzones y boleros en el programa radial Recordando el pasado. Tras el recuerdo, se evade de la realidad mientras el devenir comunitario se regenera. La importancia-sin plagiar a Vergés-evidencia que solo cenizas hallarás en la República Dominicana tras los treinta y un años de dictadura.

Dentro de su diálogo con Tres tristes tigres, La importancia de llamarse Daniel Santos también celebra la época de oro de los años cincuenta, cuando el bolero irrumpe las noches de bohemia en el Club Tropicana en Cuba. Del choteo y de la bachata entre un cubano procastro y un cubano marielito emerge esa imagen comunal de la nación. ${ }^{5}$ A pesar de la discrepancia política entre los compatriotas, la nostalgia, la indulgencia del pasado y la necesidad de pertenecer a una nación les permite la reconciliación y el flujo de los emblemas nacionales. Hablar de la bolerista Rita Montaner, de Eliseo Grenet, de Alicia Alonso y de la Virgen de la Caridad del Cobre les permite restituir la perennidad de la Cuba precastrista dentro de la coyuntura histórica gloriosa que se desea celebrar. Su choteo y bachata no tan solo les permite al bolero y a Santos ser una experiencia cultural comunitaria, sino que fungen como árbitros de ideologías reconciliables tras recordar el pasado dentro de las circunstancias del presente. Estos dos cubanos en el "Ditirambo habanero", como Silvestre y Arsenio Cué en Tres tristes tigres, promueven una resistencia que fragua la transposición del pasado en el presente mediante la obliteración del presente inmediato. Hablar de bolero y de Daniel Santos es solo el pretexto que permite la circulación de la nostalgia para luego devenir en la idealización y en la indulgencia del pasado de Cuba.

Tras esta argumentación, propongo que la resemantización que la literatura le otorga al bolero lo configura como discurso político que devela los procesos históricos continentales por su difusión simultánea precisamente entre los años treinta y sesenta en que el bolero se difunde con fervor mientras ocurren los desencuentros y revoluciones políticas en Hispanoamérica. Así, vivir en "la América en español” se convierte en una pasión redentora de los rumbos tomados (131). Como "boleriza” Sánchez tras su viaje, durante esos años se suscitan las dictaduras de Batista (1952-58) y Castro (1959-) en Cuba, y de Trujillo en la República Dominica (1930-61). Puerto Rico inicia su nueva relación estadolibrista con los Estados Unidos en 1952. Los Somozas inician su oligarquía en Nicaragua en 1937. Venezuela reinicia otra dictadura tras derrotar al presidente Rómulo Gallegos en 1948. El Salvador enfrenta guerras civiles en 1932. Panamá no goza a plenitud de los beneficios del canal. Así, la “América en español” se convierte en una experimentación y convulsión política (Sánchez 131). Sánchez lo confirma mientras escribe la supuesta hagiografía laica de Santos.

La autorreferencialidad que emerge del bolero no solo canta y dramatiza los problemas de neocolonialismo y dictaduras en el Caribe, sino que también textualiza las otras especificaciones históricas que obliteran el destino de las naciones. Tras la apropiación del bolero se crea una nueva forma de leer los des/encuentros continentales porque su tragedia implica un drama que trae consigo un irreversible dolor para las naciones y sus sujetos. Sánchez, el viajero, evidencia cómo estas transformaciones políticas responden

\footnotetext{
${ }^{5}$ Se estima en unos 125,000 personas la tercera ola de emigrantes cubanos "marielitos" que salió del
} puerto de Mariel en el año 1980. Consúltese Domínguez (145) y Arenas (297). 
a réplicas de capacidad simultánea y ubicuidad cíclica en Hispanoamérica. No importa si la nación experimenta imperialismo, caudillismo, dictadura, neocolonialismo, subdesarrollo, emigraciones, tropiezos en su implementación democrática, guerra civil o gobierno militar, la problemática reconstructiva de la nación se convierte en una experiencia repetitiva continentalmente. El drama de éstos así podría convertirse en materia prima de boleros porque vocalizarían de igual forma las tragedias, opresiones y desenfrenos con la misma pasión con que sus sujetos experimentan sus relaciones amorosas. De estas historias políticas simultáneas se perfilan unas naciones en reproducción infinita de su existencias. Así lo expresa Sánchez: "La América cuya industria es la miseria [...] La América que produce monstruos cuando opta por soñar la razón [...] La América amarga, la América descalza, la América en español” (130-1). Recurrir al bolero y a Daniel Santos no es sino representarlo a través de la manifestación popular común a todos ya que ambos fungen como texto cultural que transmite con vehemencia la violencia desatada y los júbilos de su especificación histórica. En palabras de Luis Rafael Sánchez en La importancia de llamarse Daniel Santos: “Que la música tiene el albedrío de resucitar -Pasado, levántate y anda” (102).

¿HACia UnA PoÉtiCA DEL BOLERO EN LA NARRATIVA CARIBEÑa?

¿Es este el desenlace de la historia de un amor como no habrá otro igual? ¡No! Como cantan los textos, el bolero pluraliza las voces que enuncian su paroxismo al vivir el romance, al cantar la patria, al tartamudear la transgresión porque ni el significado ni el signo admiten el absolutismo, sino que su pluralidad se volatiza bajo la evolución que apropia y desapropia, que construye y reconstruye, que deforma y reforma. Dentro de esta dialéctica se fraguan las emboscadas que proponen al bolero como cuerpo político y texto cultural caribeño. Precisémoslas sin precisar. La calidad proteica enuncia su hipercodificación.

¿Cómo el bolero se convierte en una configuración política de la nación? Este se proclama como texto cultural que ausculta la revisión histórica fundacional, el destino de las comunidades representadas y los registros que los asocia y desasocia de otras comunidades. Tras la auscultación se produce la imaginación comunitaria y fluye su intrahistoria: de dónde son, cómo es su presente, hacia dónde se dirigen. Las respuestas y preguntas en continua ebullición emergen como resultado de su simultánea ubicuidad en la búsqueda infinita del porvenir. Como resultado, eclosiona el laberinto de rumbos presentes y futuros dentro del devenir regenerativo de las naciones.

Tal pluralidad eclosiona con un trasfondo emblemático propio de las pasiones nacionales desatadas en el Caribe. La historia de una amor como no habrá otro igual va más allá porque se reinvierte la amada o el amado por la patria. La reinversión intenta registrar las homogeneidades y las heterogeneidades caribeñas desde su fundación hasta su evolución cara al siglo xxi. Y tras de esto encontramos la apropiación del bolero en la literatura caribeña como canta Rafael Hernández, preciosa te llaman los bardos que cantan tu historia. Así, Sarduy, Cabrera Infante, Vergés, Sánchez y Montero bolerizan pasiones, júbilos, desengaños, desafíos, frenesíes y agravios que enfrentan las Antillas y el continente hispano. Por tanto, ¿cuál otro género de cultura popular para apropiarse y 
develar escrituralmente las apasionadas historias y los convulsos procesos que movilizan las reedificaciones antillanas y continentales? Sólo el bolero. Como invención del Caribe, específicamente Cuba crea el género décadas después que los franceses y sus esclavos llegan a Santiago tras las insurreciones de independencia en Haití y están en contacto con los esclavos afrocubanos y los españoles. Luego, Puerto Rico, México y la República Dominicana aportan sus registros. Así develan cuánto mestizaje, sangre y pasión conjuga su invención.

El bolero "Caribe soy” parece ser la encomienda intertextual que devela este espacio como "la tierrra del amor, [...] la tierra donde nace el sol, donde la palmeras se mecen airosas al soplo del mar”. Los textos imaginan, entonces, su comunidad antillana y debaten la conjunción racial, la aportación cultural española, taína y africana, la intervención norteamericana, las causas y efectos de la dictadura, y la nostalgia e idealización de la patria, entre otros asuntos. En fin, el bolero les permite a los textos una configuración caribeña para enunciar su auténtica y móvil expresión comunitaria a través de un emblema distintivo. Este no solo distingue lo que Sánchez llama “la América en español” (131), sino que también enuncia con frenesí los procesos de violencia, apropiación, consumo, unificación y reproducción del Caribe y de Hispanoamérica en su constante revitalización.

Plural resulta la apropiación del bolero cuando documenta los asuntos eróticos cuyas historias privadas revelan más específicamente la nación-continente. Desde su pluralidad, emerge la exposición de una política patriarcal, la transgresión de ese patriarcado, la propagación ideológica para reformar la poética amatoria y el cuestionamiento de la hegemonía sexual. ¡Cuánta batalla entre los sexos! Sin duda la sexualidad caribeña también se moviliza apasionadamente, demostrando así su inconformidad con las regulaciones de su presente. Desde una configuración patriarcal, la pluralidad del bolero como intertexto podría adoptar la política confinatoria femenina. Como en el bolero “Diez minutos”, el sujeto masculino podrían enunciar los versos “quédate conmigo, tú no te me vas, pase lo que pase, digan lo que digan, tú me perteneces, esa es la verdad”. Dentro de su configuración patriarcal, éstos reduplican las expectativas de sumisión y de ausentismo femenino mediante su absolutismo masculino y asimetría entre los sexos. Esta asimetría representa la institución patriarcal como omnipotencia propia y a la mujer como el sujeto subordinado a la omnipotencia. Como resultado de la tradición, se asociaría a la mujer con toda ilegitimidad e incompetencia al confinársele o tras negarle su participación en las actividades públicas que otorgan prestigio al hombre.

Así, el bolero como manifestación y reproducción dentro del espacio público o privado establece una política pública de la mujer como deleite sexual al servicio masculino. Sin importar su asociación con el bolero, la mujer del hogar, la fanática de boleros o la desertora del hogar patriarcal quedan confinadas a una moral sexual. Cualquier intento de transgresión anularía la expectativa social organizada para el cumplimiento de su virtual función: esposa fiel, madre ejemplar, mujer (re)productiva. Si se comete la transgresión, se configuraría a la mujer como la puta del choteo, que como las boleristas de los textos, ofrecen múltiples diversiones. Tal diferencia no propicia movilidad ni para la cabaretera ni para la virtual por la sujeción masculina.

Esta configuración patriarcal fragua a su vez su reverso. En otros textos, el sujeto desertor de los paradigmas confinatorios consume el bolero y reproduce su propia versión 
de la cultura popular masiva, configurándola así como dispositivo transgresor del patriarcado. Su fijación en la memoria podría llevarla a cantar "Soñar”, y así enunciar "tu voz se apagó para mí” a quien antes cantó “tú me perteneces, esa es la verdad”. La enunciación de la transgresión podría no resultar tan espontánea ni tan firme como la enunciación de quien se reproduce en una orden. No obstante, la disidencia crea sus espacios, incurre en actos rebeldes y oblitera la inmaculada concepción social del patriarcado y de las organizaciones públicas. Curiosamente la disidencia femenina no proviene de fuentes trascendentales, ni de modelos literarios, ni de movimientos feministas, sino que surge del veto del espacio público que les ha negado otras potencialidades que no sea la domesticidad. Esta experiencia vicaria de su marginalidad y la cultura popular consumida se convierten en las bases fundadoras que organizan su resistencia. Por tanto, el bolero hace reventar el vigoroso deseo confinado e invierte el "orden” en desorden, la mesura en exceso, la pertenencia virginal masculina en pertenencia virginal femenina. La violencia generada embiste contra la magnificencia masculina y el acondicionamiento femenino. De este modo, la cultura popular masiva podría satisfacer las necesidades sicológicas de aquellos sujetos rebeldes en contra de la hegemonía dominante. La rebeldía se dirige contra quienes confabulan la hegemonía debido a que tal "verdad" descansa en el absolutismo inadecuado y discriminador de diferencias. La mujer disidente tartamudea un ¡no!, porque su configuración humana y social no fluye paralelamente a la moral sexual organizada.

El heroísmo femenino en progreso se basa en el desmantelamiento de la seguridad del espacio privado, certificando así que sus deseos desde la calma del hogar son tan propios como los del hombre desde su calle. También prueba que aunque haya una moral sexual férrea que condene su disidencia, ella glorifica su individualidad antes de glorificar el absolutismo del patriarcado que socava sus facultades. En este proceso, el bolero acude en su asistencia liberando pasiones, avivando el cuerpo, reafirmando deseos, instaurando un eterno lenguaje, derrumbando una ideología y creando otras. Tal proceso, promueve modelos femeninos con virtudes y defectos pero desde las plataformas reconstruidas por ellas y no desde los valores edificados por el hombre o por las organizaciones de poder.

La configuración política adjudicada al bolero muestra que éste no es solo un discurso que documenta la poética amatoria caribeña, sino que dentro de su documentación, el bolero se ilustra como discurso crítico de una forma específica del sujeto hispanoamericano para manifestar su sexualidad, su legitimidad social, su inscripción en esa comunidad que concibe la moral sexual de una forma y no de otra. Tal discurso crítico deja en entredicho la masculinidad exacerbada, la domesticidad confinatoria y la hegemonía cultural sexual por las conductas, valores y respuestas preconcebidas. Tanta batalla implica la enunciación de la inconformidad y la injusticia de confinar a una masa monolíticamente. Los textos caribeños en su empeño de criticar la práctica amatoria tradicional también adelantan una ruptura del binarismo de géneros como ideario social moderno. A pesar de que la disidencia de sus sujetos se interpretaría como un acto de violencia incomprendida por quienes organizan a su imagen y semejanza la sexualidad, éstos demuestran la intolerancia a la hegemonía sexual y a la conducta delimitada de los géneros como producto cultural. Como evidencian los transgresores, obliterar esa mímesis existencial resulta una férrea empresa humana por la consolidación generacional y la inquisición de sus organizadores. 
Por tanto, los sujetos crean, inventan, consumen y reproducen estrategias desde la consolidación que ha silenciado las diferencias. Sus estrategias se orientan hacia la instauración de una sexualidad plural que manifieste con libertad tanto la relación heterosexual como la homosexual. En vez de desplazar oficialidades, su ejercicio se dirige al compartimiento del espacio comunitario. Estos sujetos caribeños también acuden al bolero como dispensadores de paradigmas para canalizar su experiencia de amor mediante la diferencia. Así resemantizan y cantan su historia de amor homosexual o su deseo excepcional desde el silencio, la refracción y desde la felicidad y fatalidad que implica su normalidad vista como diferencia. Como su empresa de reconstrucción es en sí una rebelión violenta contra la tradición y sus organizadores, ésta se celebra con todo el arrebato y gozo del bolero como vehículo movilizador de su plenitud sexual.

Como síntesis final... ¿ ¿final? ¿Es este el desenlace de la historia de un...? No. El sujeto caribeño evidencia ese devenir primigenio, formativo, revolucionario y constantemente regenerativo de su identidad caribeña. Dentro de su apropiación del discurso del bolero para representarse a sí mismo, comparece el mérito de abolir toda poética por hacer de la pluralidad su estandarte. Una actitud contraria sería admitir el presente como repetición del futuro y no como proyección desde donde el sujeto caribeño consume, unifica y produce identidades dinámicas desde centros de homogeneidades movibles.

\section{BiBliografía}

Althusser, Louis. “Ideology and Ideological State Apparatuses”. Lenin and Ideology. New York \& London: Monthly Review Press, 1971. 127-86.

Álvarez Borland, Isabel. “Viaje verbal a La Habana, ¡Ah Vana!”. Hispamérica 11/31 (Takoma Park, MD 1982): 51-68.

Amorós, Celia. Hacia una crítica de la razón patriarcal. Barcelona: Anthropos, 1991. Anderson, Benedict. Imagined Communities. London \& New York: Verso, 1991.

Aparicio, Frances. Listening to Salsa. Hanover \& London: Wesleyan University Press, 1998.

Arenas, Reinaldo. Antes que anochezca. Barcelona: Tusquets, 2001.

Bataille, Georges. El erotismo. Antonini Vicen, trad. Barcelona: Tusquets, 1985.

Benítez Rojo, Antonio. La isla que se repite. Hanover: Ediciones del Norte, 1989.

Cabrera Infante, Guillermo. "Bites from the Bearded Crocodile”. London Review of Books 3/10 (London 1981): 3-8.

Tres tristes tigres. Caracas: Ayacucho, 1990.

Cámara, Madeline. “La mulata cubana: de la plaza al Malecón”. Cuba: la isla posible. Barcelona: Destino, 1995.

Carpentier, Alejo. La música en Cuba. México: Fondo de Cultura Económica, 1976.

Castillo Zapata, Rafael. Fenomenología del bolero. Caracas: Monte Ávila, 1990.

Clifford, James. “Notes on Travel and Theory”. Inscriptions 5 (1989): 177-88.

Coombe, Rosemary J. “Author/izing the Celebrity: Publicity Rights, Postmodern Politics, and Unauthorized Genders”. The Construction of Authorship. Martha Woodmansee y Peter Jaszi, eds. Durham \& London: Duke University Press, 1994. 101-31. 
Díaz Ayala, Cristóbal. Música cubana, del areyto a la nueva trova. San Juan: Editorial Cubanacan, 1981.

Domínguez, Jorge. “Cuba since 1959”. Cuba: A Short Story. Leslie Bethell, ed. Cambridge: Cambridge University Press, 1993. 95-166.

Foucault, Michel. Historia de la sexualidad: La voluntad del saber. Ulises Guiñazú, trad. México: Siglo XXI, 1989.

Kosofsky Sedgwick, Eve. Epistemology of the Closet. Berkeley: University of California Press, 1990.

Loyola Fernández, José. En ritmo de bolero.Puerto Rico: Ediciones Huracán-Ateneo Puertorriqueño, 1996.

McClary, Susan. Femenine Endings: Music, Gender, and Sexuality. Minneapolis: University of Minnesota Press, 1991.

Montero, Mayra. La última noche que pasé contigo. Barcelona: Tusquets, 1991.

Morejón, Nancy. “Mujer negra”. Casa de las Américas 88 (La Habana, 1975): 119-20.

Orovio, Helio. Diccionario de la música cubana. Cuba: Letras Cubanas, 1981.

Pavel, Thomas. "Fictional and the Ontological Landscape". Studies in Twentieth Century Literature 6/1-2 (Manhattan, KS 1981-1982): 149-63.

Renan, Ernest. "What is a Nation? Nation and Narration. Homi Bhabha, ed. London \& New York: Routledge, 1990. 8-22.

Restrepo Duque, Hernán. Lo que cuentan los boleros. Colombia: Centro Editorial de Estudios Musicales, 1992.

Rosaldo, Michelle Z. "Woman, Culture and Society: A Theoretical Overview”. Woman, Culture and Society. Michelle Z. Rosaldo y Louise Lamphere, eds. Stanford: Stanford University Press, 1974. 17-42.

Rico Salazar, Jaime. Cien años de boleros. Bogotá: Academia de Guitarra Latinoamericana, 1987.

Sánchez, Luis Rafael. La importancia de llamarse Daniel Santos. Hanover: Ediciones del Norte, 1988.

Sarduy, Severo. Gestos. Barcelona: Seix Barral, 1963.

Sarlo, Beatriz. El imperio de los sentimientos. Buenos Aires: Catálogos, 1985.

Sommer, Doris . Foundational Fictions. Berkeley: University of California Press, 1991. Souza, Raymond D. Guillermo Cabrera Infante. Austin: University of Texas Press, 1996.

Stolcke, Verena. Racismo y sexualidad en la Cuba colonial. Ana Sánchez Torres, trad. Madrid: Alianza, 1992.

Valerio Holguín, Fernando. "La historia y el bolero en la narrativa dominicana”. Revista de Estudios Hispánicos 23 (Río Piedras, 1996): 191-8.

Vargas Llosa, Mario. La tía Julia y el escribidor. Barcelona: Seix Barral, 1977.

Vergés, Pedro. Sólo cenizas hallarás (Bolero). Barcelona: Destino, 1980.

Zavala, Iris M. Bolero, historia de un amor. Madrid: Alianza, 1991. 